disappointing that rates are comparable to those seen in the general population. The proportion of women who had cervical cytology in the last year has improved from $47.3 \%$ to $74.6 \%$.

\section{P240 EVALUATING CURRENT CONTRACEPTIVE PRACTICE IN WOMEN ATTENDING TERMINATION OF PREGNANCY SERVICES IN GLASGOW}

Rebecca Orr*, Soosan Romel. Sandyford Sexual Health Services, NHS Greater Glasgow and Clyde, Glasgow, UK

\subsection{6/sextrans-2015-052126.282}

Background/introduction Despite free contraception in Scotland, over 12,000 terminations of pregnancy (TOP) are carried out annually at great financial cost.

Aim(s)/objectives To quantify methods of contraception in women presenting with unintended pregnancy at a large urban integrated sexual health unit, to identify reasons for failure.

Methods A retrospective case note review of a random sample of 100 women attending termination referral services between October 2013-March 2014.

Results Of attendees, mean age was 26 years. 38\% had used male condoms. 35\% "no contraception". 25\% Oral contraceptive pill. $24 \%$ of condom users and $43 \%$ of COCP reported imperfect use. Additionally, 9\% fell pregnant despite reported use of emergency contraception. $45 \%$ had undergone at least one therapeutic termination previously, of these: $22 \%$ reporting no use of contraception at time of conception. $4 \%$ no contraception ever. $44 \%$ of repeat attenders and $28 \%$ of whole sample reported using LARC methods in the past. $63 \%$ of women stated intention to undertake a LARC method post-procedure, however it is not clear if these were implemented.

Discussion/conclusion Large numbers of repeat TOPs suggests problems with uptake of reliable contraception post-procedure. Counselling at initial consultation - especially for repeat attendees; specific post-termination clinics and support; interventions and education targeted at high risk groups; and advocated use of LARC should reduce repeat procedures. LARC methods of contraception should continue to be encouraged in all females for primary prevention given their extreme effectiveness. Future studies of the actual uptake versus stated intention to use LARC may be insightful.

\section{P241 CONTRACEPTION AND CONDOM USE IN HIV POSITIVE WOMEN}

Michelle Olver*, Carys Knapper. Anuerin Bevan University Health Board, South Wales, UK

\subsection{6/sextrans-2015-052126.283}

Background/introduction The British Human Immunodeficiency Virus Association has published standards for the care of people living with HIV. Condom use is important in preventing transmission of HIV. Preconception care and contraceptive provision allow HIV positive women to plan pregnancy and reduce the risk of vertical transmission.

Aim(s)/objectives To ascertain whether HIV positive women in our service were using effective contraception to prevent pregnancy as well as consistent condom use.

Methods The notes of 61 female patients attending for regular HIV management within our health board were identified and reviewed. The data collected included documented condom use, contraceptive use and whether the method interacted with their treatment.

Results $57 \%$ of women were documented as using contraception, the intrauterine system being the most widely used. $13 \%$ did not need contraception due to the menopause or hysterectomy whilst $11 \%$ were documented as not currently sexually active. 12 women used condoms alone as contraception. All women on antiretroviral treatment were using appropriate forms of contraception. 21 women did not have documentation of condom use although 9 of those women were recorded as not having a partner.

Discussion/conclusion This audit has highlighted that our service requires better documentation of condom usage. Assumptions should not be made that people without partners are not sexually active. Contraception uptake was well documented with appropriate methods used whether on treatment or not. Due to the high failure rate of condoms, emphasis should be made on using them in conjunction with other forms of contraception.

\section{P242 STILL CHILDREN}

Miranda King, Sara Scofield, Cecilia Priestley*. Dorset County Hospital NHS Foundation Trust, Weymouth, UK

\subsection{6/sextrans-2015-052126.284}

Background/introduction Our GUM clinic holds an integrated young person's clinic (YPC). We have used a proforma for under 16s. In 2014 a national proforma for identifying risk of child exploitation, "Spotting the Signs" was published. We decided to expand the use of the proforma to $<18$ s.

Aim(s)/objectives To assess whether expanding the use of the young person's (YP) proforma would identify risk factors and vulnerabilities in 16-17 year olds that may have otherwise been missed.

Methods Casenote review of 50 consecutive YP aged 16-17 attending a YPC.

Results 45(90\%) were female. YP were at high risk of sexually transmitted infection (STI)-9(18\%) past history of STI, 15 $(30 \%)$ last sex with a casual partner, $15(30 \%)>1$ partner in last 3 months, $38(76 \%)$ no or inconsistent use of condoms. 11/37(30\%) screened were diagnosed with an STI (chlamydia 5, PID 4, warts 1, herpes 1). All reported that they felt able to say "no" if they did not want sex, including one who attended following sexual assault and 5 with a history of unconsensual sex. Other than those, no cases of sexual exploitation were identified; however risks/vulnerabilities were identified in many-19(38\%) mental health problems, 21(42\%) self-harm, 41 $(82 \%)$ regular alcohol and $8(16 \%)$ drug use, 12(24\%) low selfesteem. $12(24 \%)$ had had a previous attendance when the proforma was not used.

Discussion/conclusion Expanding the YP proforma to $<18$ s resulted in identifying a significant number of vulnerabilities and risk factors (mainly self-harm and low-self-esteem) for sexual exploitation and STIs that might otherwise have been missed.

\section{P243 "IN AND OUT" - MEASURING OUTCOMES FOR PREGNANCY PREVENTION IN FEMALES ATTENDING SEXUAL HEALTH CLINICS}

Joanna Nelson, Miranda King, Sara Scofield, Karen Kirkham, Cecilia Priestley*. Dorset County Hospitals NHS Foundation Trust, Weymouth, UK

10.1136/sextrans-2015-052126.285 
Background/introduction Our level 3 GUM clinic has held an integrated young person's clinic (YPC) since 2008. As well as STI testing, we provide all methods of contraception except intrauterine devices, for $<25 \mathrm{~s}$. Maximising the uptake of LARC is recommended as a method of preventing unplanned pregnancy. Previous audits of females attending for contraception have shown that $100 \%$ are offered LARC, but have not included females attending the YPC for other reasons.

Aim(s)/objectives To assess the utility of contraceptive methods of female patients attending and leaving the YPC, as an outcome measure for the effectiveness of contraceptive interventions.

Methods Prospective audit of 100 consecutive females attending the YPC from October 2014.

Results The average age was 19 (14-24). 77(77\%) attended purely for contraception, $11(11 \%)$ for a sexual health check and $12(12 \%)$ for both. $15 / 17(88 \%)$ of those not using contraception and 18/21(86\%) of females using condoms left the clinic with a form of hormone contraception [19/38(50\%) LARC]. On arrival 28(28\%) used oral contraception/Evra and on leaving 42(42\%). On arrival $33(33 \%)$ had LARC and on leaving $48(48 \%)$ had LARC. LARC was offered to all females not already using it, except 2 with complex medical conditions. The commonest reasons for declining were being happy with their current method$17(17 \%)$ and fear of side effects-11(11\%).

Discussion/conclusion The SRHAD proforma used by sexual health clinics only records contraception supplied. Contraception in/out is a better outcome measure of the prevalence of LARC use in a clinic's attendees, and an indicator of holistic sexual healthcare in an integrated YPC.

\section{P244 CHILD SEXUAL EXPLOITATION - REVIEW OF INFORMATION SHARING AND IDENTIFYING PATIENTS AT RISK}

Gillian Fraser*, Beverely Wilson-Brown, Fiona Fargie. Sandyford Initiative, Glasgow, UK

\subsection{6/sextrans-2015-052126.286}

Background/introduction We are a community based, multidisciplinary team providing sexual health care for 8,000 under 20s that attend our service yearly. Child Sexual Exploitation (CSE) is an increasingly recognised problem that affects young vulnerable people across the UK. Information sharing between agencies is an important factor in identifying young people who are involved in CSE and in order to improve our practice, we retrospectively reviewed case notes of those identified as vulnerable to CSE by other agencies.

Aim(s)/objectives To identify: was information shared when a risk of CSE was identified during the sexual health consultation? What is the prevalence of strong and warning signs of CSE in this population of young people attending sexual health services?

Methods Retrospective case note review using our health authority tool for identifying CSE risks.

Results 76 of the136 young people identified had attended our service. 39/76 (51\%) had at least one strong indicator for CSE. $36 / 39$ nine were known to social work. 38/39 had documented information sharing. 11/76 (14\%) had at least one warning indicator and 26/76 (35\%) had no identifiable CSE risk factors. 7/26 had information shared with social work.

Discussion/conclusion Information sharing occurred for almost all patients identified with a strong risk factor for CSE. 49\% of the young people identified by other agencies as at risk did not disclose information that strongly indicated CSE. Incorporation of the BASHH spotting the signs proforma and training to further increase staff awareness is being developed.

\section{P245 A PRAGMATIC PATIENT PATHWAY ENSURING APPROPRIATE SAFEGUARDING DECISIONS FOR CHILDREN WITH GENITAL WARTS}

Margaret Kingston*, Denise Smurthwaite, Sarah Dixon. Central Manchester Foundation Trust, Manchester, UK

\section{$10.1136 /$ sextrans-2015-052126.287}

Background/introduction Children found to have genital warts may present to doctors of various disciplines. The experience and knowledge of these doctors in the diagnosis and management of genital warts, and the need to assess for possible sexual abuse and other sexually transmitted infections (STIs) is variable. The authors have all been contacted for advice regarding the management of these children. In order to streamline this process and ensure that all children are appropriately assessed we developed a clinical algorithm.

Aim(s)/objectives To establish a pragmatic clinical algorithm incorporating safeguarding decisions for the management of children with genital warts.

Methods A group of paediatric, GUM and forensic physicians reviewed the evidence and relevant UK guidelines, consulted with other experts in the field and drafted an algorithm for the management of children with genital warts.

Results An initial algorithm was piloted by the authors and colleagues and sent to authors of relevant UK guidelines for their opinion. The algorithm was then finalised and is now in use in our region. It is presented as a simple flowchart.

Discussion/conclusion Developing this algorithm was complicated by differing views of experts in the field and the unfamiliarity of some doctors other than GUM or forensic physicians in performing genital examinations in children and taking the required tests. We have found this algorithm to be a useful framework for clinical decision making, to support safeguarding decisions and to ensure that the required steps are taken when assessing children with genital warts.

\section{P246 SURVEY OF IMPLANT REMOVALS IN A YOUNG PEOPLE'S SEXUAL HEALTH SERVICE}

F McGregor*, J Hammond, K Jones. Archway Sexual Health Centre, London, UK

\subsection{6/sextrans-2015-052126.288}

Background/introduction A trend for young people (YP) to abandon the contraceptive implant because of intolerable side effects has been noted. YP aged 21 and under attend our Sexual Health (SH) services in London for implants at a rate of 3 inserted to every 2 removed. Replacement of a removed implant is rare: 1 replacement implant to 32 removed. We decided to investigate our clinic population for this trend.

Aim(s)/objectives To identify profile of YP who have implant removals, reasons for removal and formulate on-going support mechanisms.

Methods Staff completed questionnaires on 20 implant removals to ascertain YP profiles and reasons for remova. 